\title{
Phonology and phonetics of Greek palatalisation
}

\author{
Antonis Botinis ${ }^{1}$, Anthi Chaida ${ }^{1}$, Evgenia Magoula ${ }^{2}$ \\ ${ }^{1}$ Lab of Phonetics \& Computational Linguistics, University of Athens, Greece \\ ${ }^{2}$ Department of Education, University of Athens, Greece \\ https://doi.org/10.36505/ExLing-2011/04/0010/000179
}

\begin{abstract}
The present investigation examines palatal production as well as the relation of phonology and phonetics in Greek. In accordance with one production experiment, the results indicate: (1) palatal productions that surface from one underlying segment are significantly longer than palatal productions that surface from two underlying segments, (2) palatal productions are voice assimilated with the preceding stop and fricative consonant production and, (3), the locus frequencies of male palatal productions are in the area of $1800-2000 \mathrm{~Hz}$.
\end{abstract}

Keywords: acoustics, phonology, phonetics, palatalisation, Greek.

\section{Introduction}

The present paper reports on an investigation of palatalisation production in Greek in regard to phonology-phonetics interface and the relation between underlying phonological representations and surface phonetic ones. For example, the plural of neutral nouns is formed by the addition of the monomorphemic vowel /a/ and, given that a great deal of neutral nouns end in the vowel $/ \mathrm{i} /$, production of palatalisation may be triggered in a considerable part of the Greek lexicon. Thus, words like /ku. 'pi/ "oar" and /ku.bi/ "button" in singular turn into [ku.'pça] and [ku.'bja] in plural, respectively, as a result of the application of the disyllabification and palatalisation rules (see further examples in Table 1).

Palatalisation is a major issue and has widely been discussed with reference to the phonem inventory and the phonological structure of Greek (e.g. Newton 1961, Koutsoudas, Koutsoudas 1962, Householder 1964). Its acoustic characteristics have however hardly been investigated and our knowledge is thus based on intuition and the knowledge of language.

In this investigation, we have concentrated on two main questions with reference to (1) the duration of the palatal productions and (2) the quality of palatal productions in terms of voicing. Thus, basic acoustic data are obtained, bring to bear crucial empirical evidence at the relation between underlying and surface representations.

\section{Experimental methodology}

The speech material of the present investigation consists of a set of key words in the carrier sentence ['ipe so'sta] (s/he said correct). The key words consist of neutral nouns in singular vs. plural forms, where the latter are in palatalisation context (Table 1).

ExLing 2011: Proceedings of 4th Tutorial and Research Workshop on Experimental Linguistics, 25-27 May, Paris, France 
Table 1. Underlying phonological representations (left) and surface phonetic representations (right) of neutral nouns in non-palatalisation contexts in singular and palatalisation contexts in plural.

\begin{tabular}{|c|c|c|c|c|}
\hline \multicolumn{3}{|c|}{ Phonological representation } & \multicolumn{2}{|c|}{ Phonetic representation } \\
\hline Singular & & Plural & Singular & Plural \\
\hline /ku'pi/ & "oar" & /kupi \#'a/ & [ku'pi] & [ku'pça] \\
\hline /ku'bi/ & "button" & /kubi \#'a/ & [ku'bi $]$ & [ku'bja] \\
\hline /sku' fi/ & "hat" & /skufi \#'a/ & [sku'fi] & [sku'fça] \\
\hline /klu'vi/ & "cage" & /kluvi \#'a/ & [klu'vi] & [klu'vja] \\
\hline /ku'ki/ & "bean" & /kuki \#'a/ & [ku'ci] & [ku'ca] \\
\hline /pu'gi// & "purse" & /pugi \#'a/ & [pu'ji] & [pu'јa] \\
\hline /pa'xi/ & "fat" & /paxi \#'a/ & [pa'çi] & [pa'ça] \\
\hline /tra' ji/ & "goat" & /trayi \#'a/ & [tra'ji] & [tra'ja] \\
\hline /pu'li/ & "bird" & /puli \#'a/ & [pu'li] & [pu'Ka] \\
\hline /pa'ni/ & "clouth" & /pani \#'a/ & [pa'ni] & [pa'na] \\
\hline
\end{tabular}

Five female and five male speakers of standard Athenian pronunciation, at their twenties, were asked to produce the speech material at their natural normal tempo. The speech material was produced at the recording studio of Phonetics and Computational Linguistics Laboratory at Athens University and was analysed with the Praat software programme.

Duration measurements of consonants as well as measurements of formant transitions between consonants and vowel of the second syllable were taken. Furthermore, consonants in palatalisation contexts were classified as voiced or voiceless, in accordance with visual inspection of the acoustic signal. The results of duration and spectral measurements were subjected to statistical analysis with the StatView software package.

\section{Results}

The presentation of the results will be confined to a description of the main effects of palatal productions. A qualitative analysis is presented (Figure 1) along with a quantitative analysis of palatal production durations (Figure 2). In general, the application of the palatalisation rule and hence palatalisation production has intraconsonantal as well as syllabic context effects.

The intraconsonantal effects are in the first place related to the production of stop and fricative palatal consonants, which are voice-assimilated with the preceding consonant, according to which a concentration of energy in low frequencies, i.e. a typical voice bar, is evident in voiced assimilation whereas lack of low energy is basically evident in voiceless assimilation (e.g. Figure 1,1 and 1.2). The intraconsonantal effects are also related to segmental durations, according to which palatal productions that surface from two underlying segments are significantly longer (anova, $\mathrm{p}<0.0001$ ) than palatal productions that surface from one underlying segment (see Figure 2). 

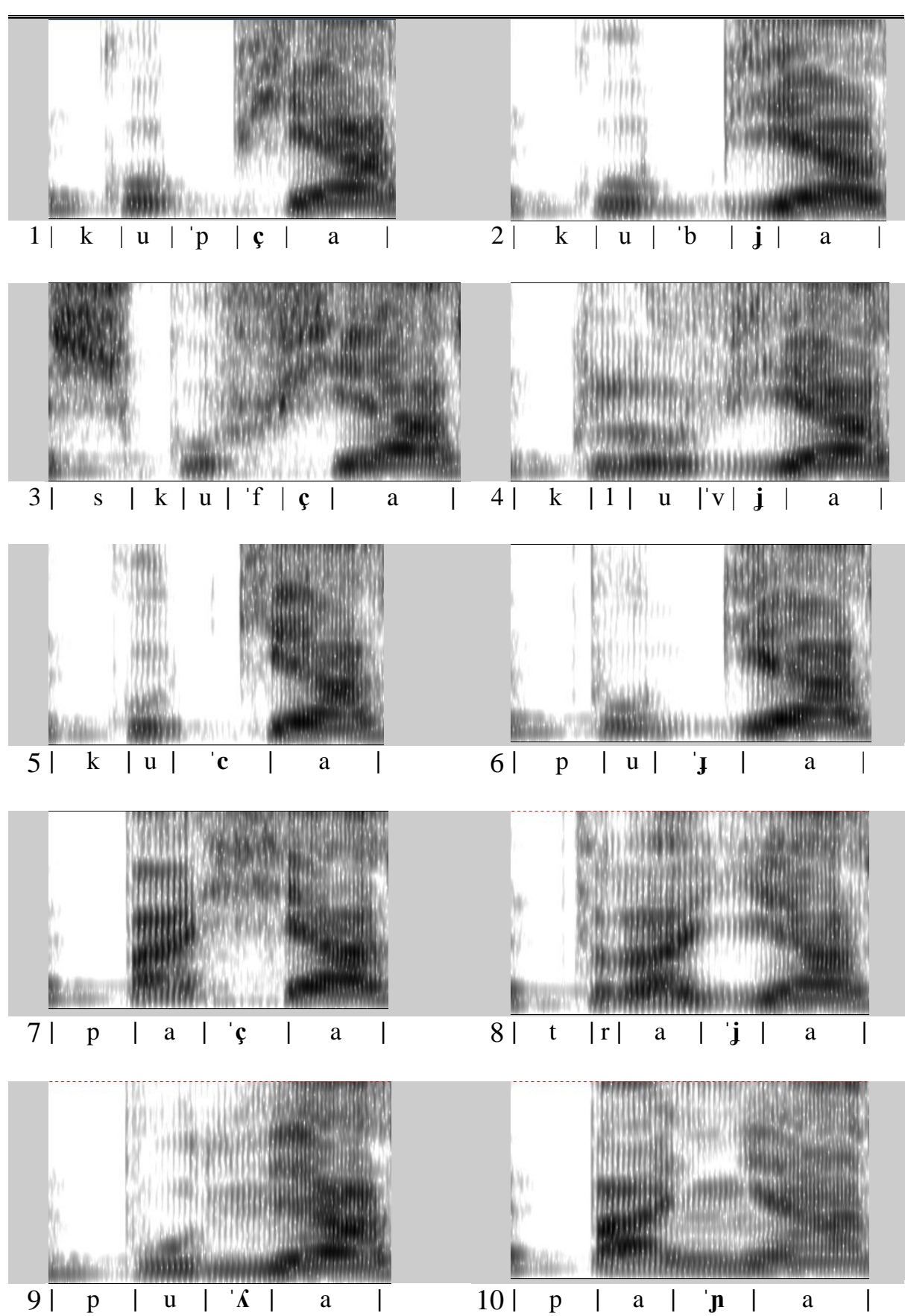

Figure 1. Exemplification of palatalisation productions (see text). 


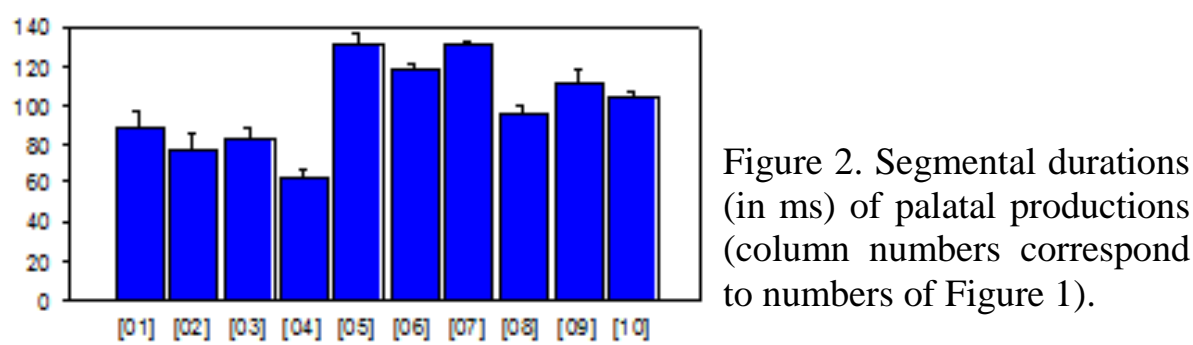

The syllabic context effects are mainly related to formant transitions and locus frequencies with reference to the following vowel in the first place. Thus, in accordance with Figure 1, the locus frequencies of palatal productions are in the area of $1800-2000 \mathrm{~Hz}$ (male voice) whereas F1 and F2 have opposite slopes, i.e. a falling and a rising, respectively. Palatal productions between vowels have however a mirror-image acoustic structure (e.g. Figure 1.7, 1.8), which indicates that palatal production is related to intersyllabic acoustic structure, in addition to intraconsonantal one.

\section{Discussion and conclusions}

The results presented in the above section indicate that the production of palatalisation maps an underlying phonological structure into a surface phonetic one, in accordance with both temporal and spectral changes in the acoustic signal. Most importantly, palatal productions that surface from two underlying segments, i.e. a consonant and a vowel, are significantly longer that palatal productions that surface from one underlying segment, i.e. a vowel. A question arises whether this phonologically-triggered lengthening effect may override any duration effect of syllabic structure and the number of consonants in syllabic onset (Botinis et al. 1999), a hypothesis which remains to be tested. In general, in accordance with the results of the present investigation, the underlying phonological structure leaves acoustic traces in surface phonetic production and the acoustic signal, which may be related to both intraconsonantal as well as intersyllabic production, formant transitions from and to preceding and following vowels, respectively.

\section{References}

Botinis, A., Fourakis, M., Prinou, I. 1999. Prosodic effects on segmental durations in Greek. Proceedings of the $6^{\text {th }}$ European Conference on Speech Communication and Technology, Eurospeech 99, vol. 6, 2475-78, Budapest, Hungary.

Newton, B. 1961. Rephonemization of Modern Greek. Lingua 10, 275-284.

Koutsoudas, A., Koutsoudas, O. 1962. A contrastive analysis of segmental phonemes of Greek and English. Language Learning 12, 211-230.

Householder, F. Three dreams of Modern Greek phonology. 1964. Word 20,3, 17 27 (Papers in memory of George C. Papageotes). 